\title{
Placer, deseo y política: la revolución estética de La Familia Galan
}

Plaisir, désir et politique : la révolution esthétique de La Famille Galan

Pleasure, desire and politics: the esthetic revolution of The Galan Family

\section{David Aruquipa Pérez}

\section{(2) OpenEdition}

Journals

\section{Edición electrónica}

URL: http://journals.openedition.org/bifea/8098

DOI: $10.4000 /$ bifea. 8098

ISSN: 2076-5827

\section{Editor}

Institut Français d'Études Andines

\section{Edición impresa}

Fecha de publicación: 1 diciembre 2016

Paginación: 451-461

ISSN: 0303-7495

Referencia electrónica

David Aruquipa Pérez, «Placer, deseo y política: la revolución estética de La Familia Galan », Bulletin de I'Institut français d'études andines [En línea], 45 (3) | 2016, Publicado el 08 diciembre 2016, consultado el 05 noviembre 2020. URL : http://journals.openedition.org/bifea/8098 ; DOI : https://doi.org/ 10.4000/bifea.8098

\section{(c)}

Les contenus du Bulletin de l'Institut français d'études andines sont mis à disposition selon les termes de la licence Creative Commons Attribution - Pas d'Utilisation Commerciale - Pas de Modification 4.0 International. 


\title{
Placer, deseo y política: la revolución estética de La Familia Galan
}

\author{
David Aruquipa Pérez*
}

\section{Resumen}

Este texto propone un recorrido por los caminos de la Familia Galan, un grupo de activistas transformistas por los derechos sexuales y de género, del cual el autor forma parte. Son famosas sus incursiones lúdicas en las calles, con su vestimenta extravagante al estilo drag queen y su participación en las comparsas de los carnavales y de las fiestas patronales de Bolivia.

Palabras clave: Bolivia, transformismo, drag queen, LGBT

\section{Plaisir, désir et politique : la révolution esthétique de La Famille Galan}

\section{Résumé}

Ce texte suit le parcours de la Famille Galan, un groupe d'activistes transformistes pour les doits sexuels et de genre, dont fait partie l'auteur. La famille Galan est réputée pour ses incursions ludiques dans les rues, avec ses accoutrements extravagants de style drag queen, et pour sa participation dans les comparses de danseurs des carnavals et des fêtes patronales de la Bolivie.

Mots-clés : Bolivie, transformisme, drag queen, LGBT

* Activista por los derechos humanos, expresidente del colectivo TLGB de Bolivia entre 2010 y 2014.

E-mail: davidctor@gmail.com 


\title{
Pleasure, desire and politics: the esthetic revolution of The Galan Family
}

\begin{abstract}
This text traces the pathways of The Galan Family, a group of transformist activists for sexual and gender rights, of which the author is a member. The Galan Family is famous for its playful raids on the streets, with an extravagant drag queen style, and for its participation in dance troupes during carnival season and the patron saint festivities in Bolivia.
\end{abstract}

Keywords: Bolivia, transvestism, drag queen, LGBT

La familia Galan deja la noche y se lanza a las calles para ver las reacciones de la gente. Toda una provocación.

Revista Escape, La Razón, La Paz, 29 de junio 2003

Escribo en primera persona porque mi acercamiento a la Familia Galan difiere a la de cada persona que le dio nombre a esta particular comunidad de afectos; por lo tanto mi relato viene desde una complejidad de actuaciones y memorias cargadas de una historicidad política. Este caminar no se entiende si no contextualizo mis primeras búsquedas de libertades para vivir y expresar mi sexualidad, mis placeres y deseos, que fueron marcadas con heridas sobre mi cuerpo. Heridas dejadas por distintas personas e instituciones, como mi entorno familiar, la escuela y la Iglesia, quienes intentaban convencerme que mis actuaciones eran «antinaturales», que yo era un «pecador» y merecía un castigo. Ahí comprendí que para desviarse de la naturalidad social, el costo que tenía que pagar era muy alto. Estas primeras marcas de disciplinamiento aún son parte de mi mapa corporal.

Para no presentar un testimonio más, cargado de lamentos y victimizaciones, les invito a recorrer por los caminos de la Familia Galan. Esta familia, sin saber lo que estaba construyendo, se constituyó en un espacio afectivo, un espacio comunitario, que ayudó a cicatrizar esas huellas que traíamos tatuadas en nuestros cuerpos. Fue un acto de ritualidad, de sanación, que desde el humor, el sarcasmo, la estética transformista 1 , y la soberbia, ¿por qué no?, nos hizo cada vez más fuertes. En esos aprendizajes coincidimos que para ser libres y felices, primero tendríamos que perder el miedo y fue eso lo que hicimos. Vamos a caminar e imaginarnos una ciudad de La Paz en constante TRANSformación.

1 Artista que cambia de atuendo y adopta ademanes del sexo contrario en un espectáculo. De este modo, «se transforma» en otra persona en un personaje al que imita, o bien en otro de creación propia. 


\section{EN EL MUNDO GAY DE LA CIUDAD DE LA PAZ, NACEN LAS GALAN}

Para conocer los primeros pasos de la Familia Galan, es importante contextualizarlos en la ciudad de La Paz de los años 1990, cuando inicié mis tránsitos por los submundos maricas, en los bares de la plaza Pérez Velasco. En el punto de encuentro denominado El Reloj, muy cerca se encontraba el bar Holiday. ¿Cómo no recordar este espacio "openmind"? No era necesariamente gay, pero sí era notoria la presencia de una diversidad de personas, entre ellas policías, maricas y prostitutas, todas hermanadas en el mismo espacio. Luego había otro lugar Ilamado La Chicharra, barcito totalmente marica, donde las parroquianas andaban acompañadas de sus «maridos»; eran dueñas de estos espacios, disfrutando la noche, bailando, a veces peleando por sus hombres. Estos dos lugares tenían una marca de clase popular. Además de estos bares, entre otros muchos, es importante recordar al Brasil y al Bolivianísimo, dos lugares que se caracterizaban por ser de clase media. Eran concurridos por gays de todas las edades, desde estudiantes a profesionales, que no querían ser confundidos con las «maricas movidas»o «mano quebrada»² de la Pérez Velasco. Ironías de clase, todas las que estaban en la Pérez también dominaban estos otros espacios. No obstante, el imaginario de clase quedaba en una ficción muy bien actuada. La característica particular de los bares Brasil y Bolivianísmo se daba por la presencia de los gays de clase media —y algunos heterosexuales curiosos_-, deseosos de diferenciarse de las travestis y maricas populares construyendo una nueva cultura gay, con códigos, lenguajes y hasta expresiones artísticas de gays transformistas. Ellos iniciaron la movida cultural, haciendo shows en un escenario que habilitaron para el deleite y disfrute de la concurrencia.

Fue en el Bolivianísimo que se realizó el primer evento de belleza transformista al estilo «barbies» y Misses heterosexuales, buscando a las transformistas más cercanas a una Lupita Jones 3 o a una Alicia Machado4; dos Miss Universo de la década de los años 1990 cuyos nombres inspiraron los seudónimos de generaciones de transformistas. Entre ellas, Diana Sofía Galan quien, junto a otras como Andrea Nicole, Lupita Jones, Bárbara Palacios, incursionó en el arte del transformismo competitivo. Todas ingresaron para ser evaluadas y devaluadas por el submundo gay que elegía a la soberana transformista. En esta tarea difícil, tenía las de ganar Diana Sofía, una de las más fuertes candidatas.

¿Quién es Diana Sofía Galan? Su nombre legal es Marco Salgueiro. Eligió su nombre inspirado en Diana, la princesa de Gales y en Sofía, la reina de España; escogió el apellido Galan porque, según él, manifestaba la elegancia masculina. Entonces era la conexión de dos beldades y el apellido Galan para jugar con el género masculino y femenino. Diana, sin pensarlo, institucionalizó el arte del

\footnotetext{
Amanieradas.

De nacionalidad mexicana, ganó el concurso de Miss Universo en 1991.

4 De origen venezolana, ganó el concurso Miss Universo en 1995.
} 
transformismo en la ciudad de La Paz, donde otras transformistas fascinadas por ella, por su capacidad transformista, se acercaron y quisieron ser parte de su entorno. Diana, o Marco Salgueiro, era bailarín del Ballet Oficial de Bolivia, uno de los primeros bailarines de entonces, ilmagínense cuando se transformaba, las actuaciones que hacía! Se hizo rápidamente una de los mejores transformistas de todos los tiempos. Diana tenía un grupo cercano de amigos, los cuales adoptaron el apellido Galan como muestra de cariño y gratitud hacia ella. Así surgen Las Galan, en 1997, con una propuesta transformista muy femenina.

\section{LAS DRAG QUEENS SALEN A PROVOCAR}

El grupo de las Galan dominó los espacios de belleza transformista por muchos años, con su tradición de producir reinas transformistas; entre ellas, Diana Sofía Galan (Miss Transformista La Paz y Bolivia en 1996), Leonela Sabatini Galan (Miss Transformista La Paz y Bolivia 1998), Satine Galan (Miss Transformista La Paz y Bolivia 2002) y así la lista sigue. Pero este tipo de transformismo, al que yo llamo «transformismo barbie» no era atractivo para muchas de nosotras.

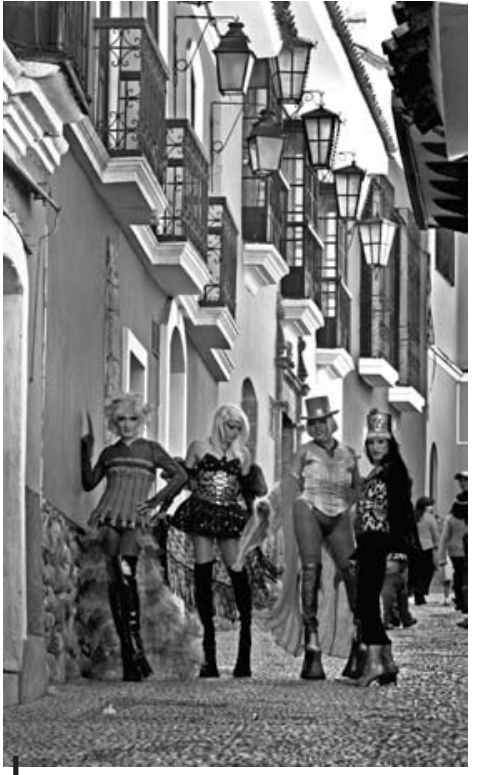

Figura 1 - Familia Galan en la Calle Jaén de la ciudad de La Paz, exposición Somos Patrimonio

(C) Tony Suarez
Cuando me acerqué a las Galan, hacia el año 1998, compartí muchas conversas con París que era mucho más atrevida y dispuesta a otras búsquedas. Juntas revisamos propuestas transformistas y finalmente adoptamos un transformismo drag queen, que es un transformismo creativo y exagerado (fig. 1). Nuestra apariencia la llevamos al extremo, dándole una connotación lúdica y transgresora, pelucas de colores, trajes estridentes. Eran memorables nuestras apariciones con los trajes coloridos y pelucas de girasoles. iFue un éxito total! Estas primeras apariciones marcaron el inicio de lo que vendría después: una exageración estética que nos marcaría como Familia hasta la actualidad. En el año 2001, empezamos nuestras apariciones públicas y masivas, alejadas del mundo gay institucionalizado, porque veíamos la necesidad de hacer otro tipo de acciones, más cercanas a la interpelación social desde las calles. Nuestra primera presentación pública tuvo lugar en el Festival de ciudadanía sexual «Placer en la Plaza», organizado por CISTAC5 5 y el colectivo de activistas MASQUE $\checkmark$ en la Paz, al que fuimos invitadas como artistas drag queens. El calendario marcaba el 2 de diciembre de 2001 cuando los colores de la diversidad sexual se instalaron en la plaza Avaroa, bajo el paragua de la ciudadanía sexual. El Festival celebraba el $53^{\circ}$ aniversario de la Declaración Universal de los Derechos Humanos. Era un día domingo, a plena luz

CISTAC Cuerpo y Territorio es una asociación civil con sede en la ciudad de La Paz que promueve los derechos humanos a partir de una reflexión política sobre las masculinidades. 
del día y al aire libre. Nunca habíamos realizado este tipo de acción pública antes. Para esta presentación asumí el nombre de Danna, en homenaje a Danna International, cantante y compositora israelí, que ganó Eurovisión en 1998, siendo la primera mujer transexual que triunfa en un evento internacional, en medio de mucha controversia. La fascinación me conectó con ella y así Danna salió a la luz pública.

Hasta este entonces, mis apariciones habían sido clandestinas, escondidas por las luces tenues y lúgubres de discotecas nocturnas y vistas solo por gente marica conocida. Este festival fue el inicio de una visibilidad pública que se ha fortalecido con los años. Una de las principales promotoras de esta aventura fue la investigadora Susanna Rance, hermana política, llamada K-os Galan. Ella se interesó por las actividades que realizábamos y comenzó a trabajar con nosotras, las drag queens de la Familia Galan. Ella nos repetía constantemente que veía en todas nosotras las teorías performativas de Judith Butler. Desde nuestros cuerpos, las esponjas, los tacos y las pelucas, éramos la deconstrucción en vivo del «género natural», decía.

\section{LA FAMILIA GALAN SE REPRODUCE}

Estos inicios irreverentes y novedosos provocaron un crecimiento rápido de la Familia Galan. Distintos personajes se hicieron parte de nuestra propuesta con un abanico de nombres como Kris-is, París, Dolor, K-os, Calipso, Pecado, Pasión, Vizio, Katrina, Alisha, Letal, Fatal, Irán, Macarena, entre otros. Parafraseando a nuestra amiga, la escritora chilena, Diamela Eltit (2007: 122) era:

un conjunto de nombres que parecen sacados de un afiebrado santoral digital, un santoral que fuera activado por el brillo de una mano enguantada circulando por una disco periférica.

Fue durante este tiempo que el grupo se diversificó: ya no estaba compuesto solo por transformistas sino también por otras personas que ayudaban o acompañaban como «fans» durante las presentaciones. Luego, la Familia Galan participó de los primeros intentos de conformar un movimiento TLGB6 en Bolivia. Entonces participamos de los congresos nacionales del colectivo TLGB como Familia Galan, cuestionando la pertenencia exclusiva a una familia biológica, abriendo las puertas a una familia política, amplia. Este autonombrarnos como familia fue también una respuesta a los grupos pro-vida7 y fundamentalistas religiosos, que defendían la familia nuclear y con quienes tuvimos muchas confrontaciones públicas. Nosotras denunciábamos las incitaciones al odio y a la discriminación que estos grupos provocaban constantemente hacia nuestro colectivo. Nuestra propuesta se fundamentaba básicamente en la decisión personal de elegir a nuestra propia familia — producto de afectos, de proyectos comunes, de la fascinación por, y del deseo del transformismo como medio de lucha interpelando el binarismo del género y de la sexualidad.

6 Trans, Lésbico, Gay y Bisexual, versión boliviana de la sigla LGBT.

7 Pro-vida califica a los activistas que militan en contra del aborto inducido. 
Nuestra sola presencia era de por sí una interpelación política. Son célebres nuestras apariciones así como las transgresiones urbanas en el paseo de El Prado, calles, plazas, teatros, supermercados, discotecas y ferias públicas. Hemos irrumpido en distintos lugares con nuestra reflexión, escandalizando a la población boliviana. Incluso, atravesamos las fronteras de nuestro país con nuestra propuesta. El principal lugar de provocación de las drag queens en la Paz fue la plaza Murillo, frente al palacio presidencial, símbolo del poder. En este lugar se concentran las decisiones de exclusión, pero también las conquistas de libertades y derechos. Entonces era este espacio el territorio elegido para expresar nuestra libertad frente al poder estatal, desde nuestros cuerpos transformados, ejerciendo nuestra ciudadanía como bolivianos/as. Algunas veces fuimos expulsadas de esta plaza; otras sin éxito porque la población era nuestro principal escudo. Las voces de la ciudadanía se unían y lograban empujar a los policías, recordándoles que somos parte de esta ciudad y que teníamos derecho de estar allí. Estas muestras de afecto de unos, de rabia y terror de otros, fortalecían a la familia Galan. Éramos la posibilidad de libertad y de justicia.

\section{LOS TACONES SON NUESTROS INSTRUMENTOS DE PODER}

Como Familia Galan, dejamos entonces de ser un grupo de transformistas cercanos a la figura «barbie» para inclinarnos hacia figuras andróginas, zoomorfas, drag queens, con pelucas coloridas y trajes galácticos. Éramos unas figuras lúdicas y vistosas. Encima de nuestros tacones de 30 o $40 \mathrm{~cm}$, podíamos tener un dominio total de la gente y del espacio, los tacos nos daban poder. Continuábamos conquistando espacios, las calles eran nuestro territorio, aunque a veces no faltaba uno que gritaba: «maricones». Entonces, todas le apuntábamos la mirada al agresor desde la altura de nuestros tacos y escapaba muerto de miedo; la gente se reía del victimario: no sabía cómo desaparecer del lugar. Era estratégica la altura, nos daba ese poder de ser visibles a una gran distancia.

Nuestras presencias se tornaron imprescindibles en las ferias culturales dominicales en el Prado de La Paz. Incluso fuimos nombradas en distintos discursos públicos como patrimonio paceño por la autoridad municipal. Salíamos en diferentes medios de comunicación. Éramos un ícono de la diversidad de nuestra ciudad. La fama alcanzada por la Familia Galan nos obligó a asumir con seriedad nuestro rol como activistas. Ya no eran solamente los espacios sociales los que nos requerían, sino también el mundo académico, mediante apariciones y presentaciones como drag queens, transformistas, drag monsters, drag animals, andróginos y groupies, en universidades, simposios, foros y demás eventos. Los tacones, el maquillaje, las pestañas y los trajes nos acompañaban en acciones públicas y debates sobre los cuerpos politizados en la sociedad boliviana. El activismo desde las calles comenzó a cuestionar las cómodas acciones de los grupos gays que desde el escritorio institucionalizado pensaban transformar la sociedad. Nosotras, con la rebeldía que nos caracterizaba, discutíamos y echábamos en cara que la transformación se da en las calles y no en los espacios cerrados que ellos empezaban a formalizar, con una política de enclaustramiento social: los «guetos gays». 
La Familia Galan ha tenido una gran influencia dentro del movimiento TLGB de Bolivia puesto que, a través de nuestra agenda, otras agrupaciones — tales como Las Divas, la Familia Holiday, la Familia Anderson y otras- se apropiaron del transformismo drag queen. Las drag queens desde entonces hasta la actualidad dominan las acciones TLGB, desde las marchas del orgullo Trans, Lésbico, Gay y Bisexual en Bolivia hasta la presencia en las fiestas populares, que es una nueva marca de aparición reivindicativa. La Familia Galan fue ingresando en los espacios de arte y cultura, montando exposiciones fotográficas en distintos espacios culturales, como la muestra «Lenguajes Corporales: Transgresión Transformista» (2003), «Mi otro yo» (2004), «Mi rostro refleja mi libertad» (2010), «Somos Patrimonio» (2012), «La China Morena: Memoria Histórica travesti» (2013), «Metamorfosis» (2014), «Memorias Colectivas» (2015). También presentamos obras de teatro como «Las memorias de Katherine» (2004) con gran repercusión social y mediática, las «Malcriadas» (2006) basadas en «Las Criadas» de Jean Genet, y el «Fango Negro» (2004). En estas obras, adaptamos los diálogos de los personajes femeninos a los de travestis y transformistas, interpretadas por la Familia Galan, visibilizando historias, memorias, prácticas y discursos de nuestra comunidad. La intención era provocar e ingresar a estos espacios artísticos reservados únicamente para elencos teatrales reconocidos. La presencia pública de la Familia Galan, cada vez más protagónica, es ahora parte de la agenda cultural paceña y boliviana.

\section{CONQUISTA DE LAS FIESTAS POPULARES}

Nos fue insuficiente limitarnos a la estética transformista drag queen. Otro espacio importante de irrupción de La Familia fueron las fiestas populares, nuevos escenarios de conquista a través de la danza de la kullaguada 8 y el personaje del waphuri Galan (figs. 2, 3). El waphuri es el jefe de los hilanderos de la kullaguada que es parte del Carnaval de Oruro, una de las festividades más importante de Bolivia, denominada Obra maestra del Patrimonio Oral e Intangible de la Humanidad por la UNESCO desde el año 2002. Obviamente, le dimos al personaje del waphuri valores maricas y una nueva estética con tacones, el traje ceñido al cuerpo, incorporando elementos como la manta, el corset y los volados, además del uso del maquillaje. Integrar a esta festividad el waphuri Galan provocó mucha tensión. Estábamos conscientes que el costo de «mariconizar» a un personaje masculino como es el waphuri, figura central de la virilidad y del poder, podría provocar la expulsión de la fraternidad. Para los folcloristas tradicionales, estábamos tergiversando la cultura y desvirtuando a este

8 La danza de la kullaguada tiene raíces prehispánicas; está vinculada a la actividad del tejido como práctica ceremonial y cultural que hombres y mujeres de los pueblos indígenas realizan en sus comunidades. En la actualidad, esta manifestación se ha convertido en una danza «mestizourbana», donde se ha configurado una coreografía ágil y coqueta, vinculada a la producción textil y al amor en pareja. Se baila en parejas distribuidas en dos filas centrales de mujeres acompañadas por dos filas laterales de varones. Esta tropa de kullaguas es dirigida por el waphuri, guía y maestro de los hilanderos, quien Ileva un traje ostentoso y una rueca más grande. Este personaje «masculino» heterosexual representa el liderazgo, encabezando la tropa de bailarines (Aruquipa et al., 2012: 53). 


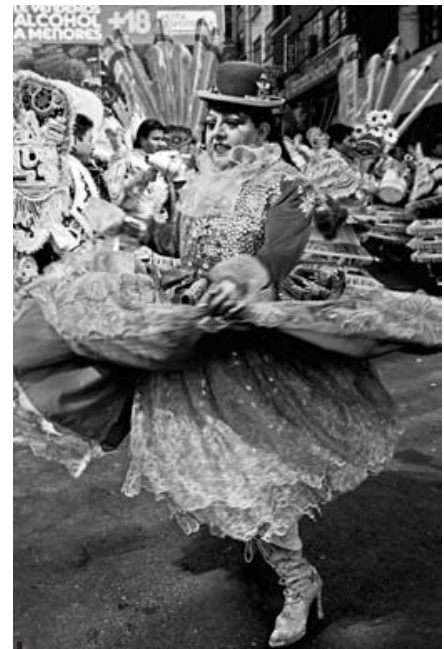

Figura 2 - Danna Galan, Gran Poder 2012, recuperando el personaje de la China Naupa. Fraternidad Vacunos

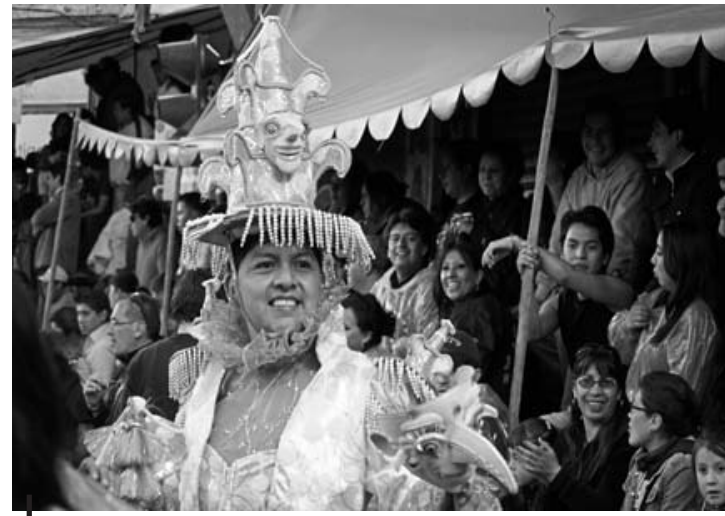

Figura 3 - El waphuri Galan, Carnaval de Oruro 2012 (C) Pablo Céspedes

(C) Tony Suarez

personaje. De hecho, al inicio, nos amenazaron con prohibirnos bailar, pero al final quedó solo como comentarios. De todas maneras, ya la gente esperaba al waphuri Galan, ya se había hecho parte fundamental de la kullaguada. De ahí en adelante, ya no fuimos los cuatro waphuris iniciales: cada vez más jóvenes de la comunidad TLGB recrean el personaje en otros grupos de kullaguadas y en otras festividades. Así, la presencia de este personaje ha fortalecido nuestra presencia en la cultura popular, abriendo la posibilidad de revisar los aportes históricos y culturales de nuestra población TLGB en las fiestas populares para saber quiénes nos habían antecedido en estas presencias y desobediencias. En este afán, nos encontramos con el cantante y compositor Gerardo Rosas —nacido en los años 1920 en Sucre, una de las ciudades más conservadoras de Bolivia—, que ha aportado a la cultura popular desde el canto y baile de las cuecas y bailecitos chuquisaqueños. Poco se ha escrito de este singular artista marica de antaño, seguro por esconder o anular la presencia del llamado q'iwa9 Gerardo en el repertorio popular. Recuperar su historia junto a la de otros artistas como Jaime del Río, otro artista homosexual contemporáneo de Gerardo, nos permitió hacer una arqueología de nuestros antepasados, de aquellos que de alguna manera estaban precediendo nuestras luchas.

A estos cantantes populares posteriormente siguieron otros homosexuales, creando el personaje de las chinas morenas, figuras femeninas en la danza de la

9 Existen diversas interpretaciones al respecto de este término. En la época prehispánica, se decía q'iwas a personas dotadas para relacionarse dualmente tanto con el mundo espiritual masculino como femenino. En la Colonia, este vocablo se trastocó hacia la interpretación española y cristiana de sodomita, homosexual o maricón; a la fecha conserva este uso peyorativo en el sentido social común. 
morenada (ver Aruquipa et al., 2012). Su presencia en los años 1960 y 1970, en las fiestas populares como el Carnaval de Oruro, el Gran Poder de La Paz y otras, fue revolucionaria: una provocación social desde una estética irreverente donde expresaban su orientación sexual, en y desde la cultura popular. Marcaron a una época desde una práctica política emergiendo desde la provocación que podríamos equiparar con la revolución sexual que se estaba dando en países occidentales en esas épocas. En Bolivia, se estaba desafiando a códigos conservadores de la moral sexual desde manifestaciones culturales públicas, modificando la historia política de la cultura popular. La presencia de las chinas morenas es emblemática porque ha permitido que presencias posteriores y actuales tengan una continuidad en el tiempo, pues la memoria funciona como un camino abierto que deja posibilidades para nuevos personajes. La estética travesti, los aportes maricas a la danza, los movimientos sicalípticos, el beso de una china morena a un presidente 10 en una época de dictadura, fortalecieron nuestro discurso político, reforzando las provocaciones maricas a un sistema dominante y conservador.

\section{SOMOS HIJAS ILUSTRES DEL ATREVIMIENTO}

La Familia Galan somos muchas y con distintos intereses. Por lo mismo he relatado desde mi experiencia algunos pasajes históricos que sostienen un accionar político, manifestado desde la academia y desde el activismo, y que materializamos junto con Pablo C. Vargas y Paula Estenssoro (Fatal Galan) en el libro Memorias Colectivas (2012). La Familia Galan somos fruto de una forma de ver, amar y vivir en familia, caminando por las calles de la ciudad de La Paz donde las libertades son conquistas del día a día. Hemos transformado formas de ver y entender las sexualidades y los géneros posibles, poniendo constantemente en cuestión constante las miradas binarias y esencialistas del sistema sexo-génerosexualidad, utilizando el cuerpo como un discurso político, un espacio de lucha, como un desafío actual e histórico a las miradas conservadoras. Con ello, hemos penetrado las venas más profundas de nuestra sociedad y desde nuestra cultura dialogamos y actuamos con toda la población que se atreve a romper con los prejuicios aún existentes. Hemos sabido utilizar el transformismo como una herramienta de lucha política como lo expresaba, en 2013, Alfredo Muller, pintor controversial boliviano, en la inauguración de una muestra conjunta denominada Estéticas Galan:

La gente reconoce a la Familia como los íconos trans bolivianos, asociándolos con el ejercicio de derechos y libertades. Son un movimiento

10 Anteriormente, la fiesta del Gran Poder se desarrollaba solamente en el barrio popular paceño de Chijini. Luego, las comparsas ingresaron al centro de la ciudad. Este acercamiento al poder político se hizo a costa de la expulsión de las travestis de la fiesta. Todo esto se representa en el mítico beso que una china morena, Barbarella (Peter Alaiza), le dio al presidente de facto Hugo Banzer Suárez en la Entrada del Gran Poder de 1975. Este hecho ha quedado en la memoria de toda la población homosexual de entonces, porque este beso fue la excusa para la expulsión y persecución de la población homosexual, y reordenar la fiesta desde una mirada heterosexual. 
estético con una amplia acción política y propuesta social revolucionaria que se ha apropiado, simbólica y físicamente, de un espacio en el corazón del público. No solo como transformismo, sino como una ideología que intenta romper con lo supuestamente normal sobre la cultura, la educación y la información; además de la sexualidad y el género para repensar desde otros enfoques una verdadera revolución social.

Encuentros como este se fueron dando con muchos otros artistas, fotógrafos y literatos. Han permitido que nuestra presencia se vuelva imprescindible tanto en las fiestas populares como en las galerías de arte de Bolivia, donde nuestro trabajo permite interpelar lo «políticamente correcto» (fig. 4).

Continuamos reflexionándonos y teorizando sobre nuestras acciones. No somos víctimas del sistema, más bien lo transformamos. No somos las hijas olvidadas del sistema, nos apropiamos de los espacios que nos corresponden. Somos una familia porque así lo decidimos, estamos en muchos países, actualmente Diana Sofía Galan se encuentra en España junto con otras hermanas: Jolie, Calypso, Miranda, Lulú, Rosa y Delito Galan. Macarena está en Argentina, en Estados Unidos, Bolivia Galan, y en La Paz, seguimos París, Alisha, Letal, Fatal, Katrina, Ila, Kea Grissi, Pecado, Vizio, Malicia y yo, Danna Galan. Espero que este breve viaje, por pasajes, memorias y escritos, seduzca y genere la necesidad de saber más sobre nosotras. Somos atrevidas, regias, arrogantes y siempre FAMILIA GALAN.

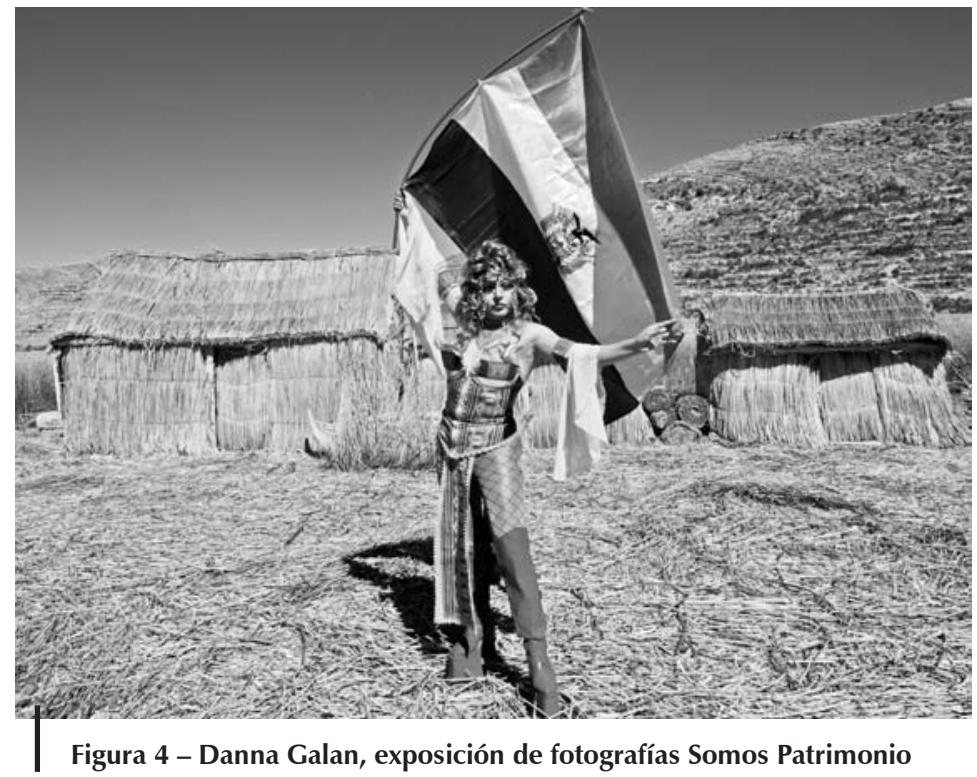

(C) Tony Suarez 
Placer, deseo y política: la revolución estética de la Familia Galan

\section{Referencias citadas}

ARUQUIPA, D., ESTENSSORO, P., VARGAS, P. C., 2012 - Memorias colectivas. Miradas a la Historia del movimiento TLGB de Bolivia, 363 pp.; La Paz: Conexión Fondo de Emancipación, Serie Estudios e Investigaciones 5.

ELTIT, D., 2007 - La Familia Galan. In: Cruce de lenguas: sexualidades, diversidad y ciudadanía (R. Olea \& K. Araujo, eds.): 121-126; Santiago de Chile: Universidad Academia de Humanismo Cristiano. 